\title{
Comparison of renal histopathology and gene expression profiles between severe COVID-19 and bacterial sepsis in critically ill patients
}

Meint Volbeda', Daniela Jou-Valencia', Marius C. van den Heuvel ${ }^{2}$, Marjolein Knoester $^{3}$, Peter J. Zwiers ${ }^{4}$, Janesh Pillay ${ }^{1}$, Stefan P. Berger ${ }^{5}$, Peter H. J. van der Voort ${ }^{1}$, Jan G. Zijlstra ${ }^{1,4}$, Matijs van Meurs ${ }^{1,4}$ and Jill Moser ${ }^{1,4^{*}}$ (1)

\begin{abstract}
Background: The mechanisms driving acute kidney injury (AKI) in critically ill COVID-19 patients are unclear. We collected kidney biopsies from COVID-19 AKI patients within 30 min after death in order to examine the histopathology and perform mRNA expression analysis of genes associated with renal injury.

Methods: This study involved histopathology and mRNA analyses of postmortem kidney biopsies collected from patients with COVID-19 $(n=6)$ and bacterial sepsis $(n=27)$. Normal control renal tissue was obtained from patients undergoing total nephrectomy $(n=12)$. The mean length of ICU admission-to-biopsy was 30 days for COVID-19 and 3-4 days for bacterial sepsis patients.
\end{abstract}

Results: We did not detect SARS-CoV-2 RNA in kidney biopsies from COVID-19-AKI patients yet lung tissue from the same patients was PCR positive. Extensive acute tubular necrosis (ATN) and peritubular thrombi were distinct histopathology features of COVID-19-AKI compared to bacterial sepsis-AKI. ACE2 mRNA levels in both COVID-19 (fold change $0.42, p=0.0002$ ) and bacterial sepsis patients (fold change $0.24, p<0.0001$ ) were low compared to control. The mRNA levels of injury markers NGAL and KIM-1 were unaltered compared to control tissue but increased in sepsis-AKI patients. Markers for inflammation and endothelial activation were unaltered in COVID-19 suggesting a lack of renal inflammation. Renal mRNA levels of endothelial integrity markers CD31, PV-1 and VE-Cadherin did not differ from control individuals yet were increased in bacterial sepsis patients (CD31 fold change 2.3, $p=0.0006$, PV-1 fold change 1.5, $p=0.008$ ). Angiopoietin-1 mRNA levels were downregulated in renal tissue from both COVID-19 (fold change 0.27, $p<0.0001$ ) and bacterial sepsis patients (fold change $0.67, p<0.0001$ ) compared to controls. Moreover, low Tie2 mRNA expression (fold change $0.33, p=0.037$ ) and a disturbed VEGFR2NEGFR3 ratio (fold change $0.09, p<0.0001$ ) suggest decreased microvascular flow in COVID-19.

Conclusions: In a small cohort of postmortem kidney biopsies from COVID-19 patients, we observed distinct histopathological and gene expression profiles between COVID-19-AKI and bacterial sepsis-AKI. COVID-19 was associated with more severe ATN and microvascular thrombosis coupled with decreased microvascular flow, yet minimal

*Correspondence: j.moser@umcg.nl

1 Department of Critical Care, University of Groningen, University Medical Center Groningen, Hanzeplein 1,9713 GZ Groningen, The Netherlands

Full list of author information is available at the end of the article permits use, sharing, adaptation, distribution and reproduction in any medium or format, as long as you give appropriate credit to the original author(s) and the source, provide a link to the Creative Commons licence, and indicate if changes were made. The images or other third party material in this article are included in the article's Creative Commons licence, unless indicated otherwise in a credit line to the material. If material is not included in the article's Creative Commons licence and your intended use is not permitted by statutory regulation or exceeds the permitted use, you will need to obtain permission directly from the copyright holder. To view a copy of this licence, visit http://creativecommons.org/licenses/by/4.0/. The Creative Commons Public Domain Dedication waiver (http://creativeco mmons.org/publicdomain/zero/1.0/) applies to the data made available in this article, unless otherwise stated in a credit line to the data. 
inflammation. Further studies are required to determine whether these observations are a result of true pathophysiological differences or related to the timing of biopsy after disease onset.

Keywords: COVID-19, Acute kidney injury, Bacterial sepsis

\section{Introduction}

The recent COVID-19 pandemic has resulted in major morbidity and mortality. The number of ICU-admitted COVID-19 patients developing AKI (COVID-AKI) varies per geographical area but has been reported to be as high as $20-76 \%$ [1-4] and is associated with poor prognosis [5]. The mortality of critically ill COVID-19 patients requiring renal replacement therapy (RRT) varies between 42 and $90 \%$ [4, 6, 7]. Although recent autopsy studies have provided information on the consequences of SARS-CoV-2 infection on kidney histopathology, the mechanisms driving renal failure remain poorly understood and treatment strategies aiming to limit or reverse renal failure are still lacking. Previous reports have suggested that the renal pathophysiology associated with COVID-19 is similar to that described for patients with bacterial sepsis $[8,9]$. However, studies investigating the differences and similarities have not yet been reported.

The aim of this study was therefore to collect postmortem kidney biopsies from COVID-19 patients rapidly after death in order to examine the histopathology and to integrate molecular analyses in order to gain an in-depth understanding of the possible mechanisms of renal injury and failure associated specifically with severe SARS$\mathrm{CoV}-2$ infection. In light of the discussion regarding the similarities between COVID-19 and bacterial sepsis, we compared bacterial sepsis data from previously published studies by our group [10-12] with new data from COVID-19 patients. To our knowledge, this is the first study to report renal mRNA data which combined with histopathology has enabled us to identify at least some of the molecular mechanisms associated with COVID-AKI.

\section{Materials and methods Human postmortem biopsies Control}

Normal control renal biopsies were collected from a healthy part of the kidney cortex from patients that underwent complete nephrectomy for kidney cancer $(n=12)$. Renal tissue residing as far away from the tumor as possible was collected. A renal pathologist at our hospital $(\mathrm{MvdH})$ assessed these "normal control" biopsies and considered them to be normal kidney tissue.

\section{Bacterial sepsis}

Postmortem kidney biopsies were collected from adult patients with bacterial sepsis $(n=27)$ as described in detail elsewhere [10]. Patients with bacterial sepsis who had pre-existing chronic kidney disease, active autoimmune disorders with renal involvement, or were treated with immune-suppressive medication were excluded from this study. All patients were classified as having septic shock according to the International Sepsis Definition [13]. The extent of renal failure was classified according to the, at that time, applicable RIFLE (Risk, Injury, Failure, Loss of kidney function, and End-stage kidney disease) criteria [14].

\section{COVID-19}

Postmortem kidney and lung biopsies were collected from adult patients with SARS-CoV-2 infection $(n=6)$. The diagnosis of COVID-19 was confirmed by RT-PCR of oropharyngeal and nasopharyngeal swabs. The presence of SARS-CoV-2 was also determined in the sputum of patients. The timeline of hospitalization and SARS$\mathrm{CoV}-2$ detection is detailed in Fig. 2a. The extent of renal failure was classified according to the latest KDIGO (Kidney Disease: Improving Global Outcomes) criteria [15].

Clinical characteristics are described in Table 1. The rapid collection of postmortem biopsies was considered a limited autopsy. Permission and written informed consent were asked for, and obtained, in the final family meeting. All biopsies were taken as quickly as possible after death at the bedside in our ICU and are therefore considered "warm". The Medical Ethics Review Committee (METC) of the University Medical Center Groningen (UMCG) reviewed this study. The Central ethics Review Board non-WMO studies (CTc UMCG) has approved this study (METc 2011/372 and Research Register Number: 201900431).

\section{Tissue sampling and histopathology}

Multiple kidney biopsy tissue specimens were harvested from patients with bacterial sepsis and COVID-19 under ultrasound guidance after introducing the biopsy device (Angiotech, 14 Ga $\times 20 \mathrm{~cm}$, Tru Core II Biopsy Instrument, Gainesville, Fl) through a small skin incision. Lung biopsies were also collected from 4 of the COVID-19 patients. Biopsy tissues were either immediately snapfrozen or placed in RNAlater ${ }^{\circledR}$ (ThermoFisher Scientific, Bleiswijk, The Netherlands) solution and subsequently 
stored at $-80^{\circ} \mathrm{C}$ until RNA isolation and gene expression analysis. For histopathological analysis, additional renal biopsies were immediately fixed in $10 \%$ formalin fixative for 24-48 $\mathrm{h}$ and subsequently processed and imbedded in paraffin. Hematoxylin and eosin, periodic acid-Schiff, Jones methenamine silver, and Martius scarlet, blue stains were performed on paraffin sections obtained from all patients and controls. All sections were evaluated and scored by the same experienced renal pathologist $(\mathrm{MvdH})$ following the routine pathology procedure and therefore could not be blinded. Scoring methods were

Table 1 Patient characteristics

\begin{tabular}{|c|c|c|c|}
\hline & Control $(n=12)$ & Sepsis $(n=27)$ & COVID-19 $(n=6)$ \\
\hline Age & $59(20-79)$ & $67(40-85)$ & $65(49-78)$ \\
\hline Male:female & $5: 7$ & $17: 10$ & $4: 2$ \\
\hline SAPS II score & $\mathrm{n} / \mathrm{a}$ & $68.8(35-99)$ & \\
\hline BMI $\left(\mathrm{kg} / \mathrm{m}^{2}\right)$ & & $26.9(20.8-49)$ & $30.8(26-37)$ \\
\hline Normal weight (BMI 18.5-24.9) & & 9 & 0 \\
\hline Overweight (BMI 25-29.9) & & 14 & 3 \\
\hline Obese (BMI > 30) & & 4 & 3 \\
\hline Days in ICU & $\mathrm{n} / \mathrm{a}$ & $3.6(1-12)$ & $30(21-53)$ \\
\hline \multicolumn{4}{|l|}{ Comorbidities } \\
\hline Hypertension & 3 & 8 & 1 \\
\hline Diabetes Mellitus & 1 & 3 & 2 \\
\hline COPD or asthma & 4 & 7 & 0 \\
\hline Coronary disease & 1 & 5 & 0 \\
\hline Neurological & 1 & 3 & 0 \\
\hline Renal disease & 0 & 0 & 0 \\
\hline Vascular surgery & 0 & 2 & 0 \\
\hline Autoimmune disease & 2 & 4 & 0 \\
\hline Neoplasms (extra renal) & 4 & 4 & 0 \\
\hline \multicolumn{4}{|l|}{ RIFLE stage } \\
\hline Risk & $\mathrm{n} / \mathrm{a}$ & 0 & $\mathrm{n} / \mathrm{a}$ \\
\hline Injury & $\mathrm{n} / \mathrm{a}$ & 12 & $\mathrm{n} / \mathrm{a}$ \\
\hline Failure & $\mathrm{n} / \mathrm{a}$ & 15 & $\mathrm{n} / \mathrm{a}$ \\
\hline Loss of function & $\mathrm{n} / \mathrm{a}$ & 0 & $\mathrm{n} / \mathrm{a}$ \\
\hline End-stage renal disease & $\mathrm{n} / \mathrm{a}$ & 0 & $\mathrm{n} / \mathrm{a}$ \\
\hline \multicolumn{4}{|l|}{ KDIGO AKI score } \\
\hline 0 & $\mathrm{n} / \mathrm{a}$ & $\mathrm{n} / \mathrm{a}$ & 1 \\
\hline 1 & $\mathrm{n} / \mathrm{a}$ & $\mathrm{n} / \mathrm{a}$ & 0 \\
\hline 2 & $\mathrm{n} / \mathrm{a}$ & $\mathrm{n} / \mathrm{a}$ & 0 \\
\hline 3 & $\mathrm{n} / \mathrm{a}$ & $\mathrm{n} / \mathrm{a}$ & 5 \\
\hline Need for RRT (Yes:no) & $\mathrm{n} / \mathrm{a}$ & $12: 15$ & $4: 2$ \\
\hline Mean biopsy time (mins) & $\mathrm{n} / \mathrm{a}$ & $33(24-150)$ & $21(6-40)$ \\
\hline \multicolumn{4}{|l|}{ Microorganisms } \\
\hline Gram positive & $\mathrm{n} / \mathrm{a}$ & 12 & $3^{\#}$ \\
\hline Gram negative & $n / a$ & 23 & $1^{*}$ \\
\hline Virus (norovirus \& HIV) & $\mathrm{n} / \mathrm{a}$ & 2 & 0 \\
\hline Fungi/yeast & $\mathrm{n} / \mathrm{a}$ & 5 & 0 \\
\hline SARS-CoV-2 & $\mathrm{n} / \mathrm{a}$ & $\mathrm{n} / \mathrm{a}$ & 6 \\
\hline
\end{tabular}

ICU intensive care unit, SAPS II Simplified Acute Physiology Score II scoring system, BMI body mass index, RIFLE (risk, injury, failure, loss of kidney function, and end-stage kidney disease) classification, KDIGO AKI Kidney Disease Improving Global Outcomes acute kidney injury classification, $R R T$ renal replacement therapy, COPD chronic obstructive pulmonary disease, HIV human immunodeficiency virus, SARS-CoV-2 severe acute respiratory syndrome coronavirus 2. n/a not applicable. Microorganisms were detected in either the sputum, blood, urine or abdominal fluid

*Multi-resistant pseudomonas in blood and sputum.

" CVL or ECLS cannula-related infection with a coagulase-negative staphylococci 
performed as described previously [10] and are summarized in Additional file 1: Table S1.

\section{RNA Isolation}

Total RNA was isolated from human kidney cryosections or homogenized renal and lung biopsies using either a RNeasy Mini plus Kit or miRNAeasy Mini kit (Qiagen, Venlo, The Netherlands) according to the manufacturer's instructions. RNA concentration and purity were measured using a NanoDrop ${ }^{\circledR}$ ND-1000 ultraviolet spectrophotometer (NanoDrop Technologies, Rockland, DE), while RNA integrity was determined by gel electrophoresis.

\section{SARS-CoV-2 detection by rRT-PCR}

Five microliter ( $\mu \mathrm{l}$ ) of extract with known RNA content $(\mathrm{ng} / \mu \mathrm{l})$ was combined with $5 \mu \mathrm{l}$ DNAse/RNAse free water (Sigma, The Netherlands). SARS-CoV-2 rRT-PCR was performed on the E-gen and $\mathrm{N}$-gen as described [16], with minor modifications. The PCR reaction is a multiplex for SARS-CoV-2 and Phocine Distemper Virus (PDV) and is performed in a total reaction volume of $25 \mu \mathrm{l}$ using $10 \mu \mathrm{l}$ input and $15 \mu \mathrm{l} \mathrm{PCR} \mathrm{mix,} \mathrm{contain-}$ ing 1xTaqMan ${ }^{\circledR}$ Fast Virus 1-Step Master Mix (Applied Biosystems, Foster City, CA, USA), DNAse/RNAse free water (Sigma, The Netherlands), $400 \mathrm{nM}$ SARS-CoV-2 forward and reverse primer, $200 \mathrm{nM}$ SARS-CoV-2 probe, $300 \mathrm{nM}$ PDV forward primer (5'-cgggtgccttttacaagaac), $300 \mathrm{nM}$ PDV reverse primer (5'-ttctttcctcaacctcgtcc) and100nM PDV probe (NED-aag ggc caa ttc t-MGBNFQ). The ABI PRISM 7500 (Life technologies, USA) was used for the amplification and detection using the profile of $2 \min 50^{\circ} \mathrm{C}, 20 \mathrm{~s} 95^{\circ} \mathrm{C}$, followed by 45 cycles of $3 \mathrm{~s} 95^{\circ} \mathrm{C}$ and $32 \mathrm{~s} 60^{\circ} \mathrm{C}$. Since the RNA from kidney and lung tissues were isolated without the addition of PDV as described above, the PDV reaction was in this case redundant.

\section{Gene expression analysis by RT-qPCR}

RNA was reverse transcribed using SuperScript ${ }^{\circledR}$ III reverse transcriptase (Invitrogen, Breda, The Netherlands) and random hexamer primers (Promega, Leiden, The Netherlands). Next, complementary DNA (10 ng) was used for quantitative polymerase chain reaction (RTqPCR) using a ViiA7 real-time PCR System (Applied Biosystems, Nieuwerkerk aan den IJssel, The Netherlands). Details of the assay-on-demand primers (ThermoFisher Scientific) used in this study are described in Additional file 1: Table S2. Duplicate real-time PCR analyses were performed for each sample, and the obtained threshold cycle $(\mathrm{CT})$ values were averaged. Gene expression values were normalized to the expression of the housekeeping gene GAPDH, resulting in the $\triangle \mathrm{CT}$ value. GAPDH is an invariant endogenous control in the assay that corrects for sample-to-sample variations in RT-PCR efficiency. The relative mRNA level was calculated by $2^{-\Delta C T}$.

\section{Statistical analysis}

Statistical analyses were performed using GraphPad Prism Software v8. Data are presented as mean \pm SD. One-way analysis of variance (ANOVA) followed by Tukey's multiple comparison test was used to compare the data from bacterial sepsis and COVID-19 patients and controls. Differences were considered significant when $p<0.05$.

\section{Results}

\section{Patient characteristics}

Postmortem biopsies were collected from patients that died in the ICU with organ failure related to either COVID-19 or bacterial sepsis. Patient characteristics are given in Table 1 . Most patients included in our study were male (66\% with COVID-19) and (62\% with bacterial sepsis). However, the length of ICU stay clearly differed between the groups with the mean length of ICU stay being 30 days for COVID-19 patients (range 21-53) and 3-4 days (range 1-12) for patients with bacterial sepsis. Most, but not all, patients with bacterial sepsis were overweight (66\%), yet all patients with COVID-19 included in our study were either overweight or obese. All patients with sepsis had at least one comorbidity, whereas 2 COVID-19 patients had type 2 diabetes mellitus with one of them also having hypertension. All patients, COVID-19 and sepsis were mechanically ventilated. Four out of 6 patients were dialysis-dependent at the time of death. The other 2 patients had a creatinine level of 29 and $68 \mu \mathrm{mol} / \mathrm{L}$, respectively. One of the patients had a maximum creatinine of $175 \mu \mathrm{mol} / \mathrm{L}$ during ICU stay but was reduced to $68 \mu \mathrm{mol} / \mathrm{L}$ at the time of death. Most patients were admitted to the University Medical Center Groningen (UMCG) from a referral hospital. Oropharyngeal and nasopharyngeal swabs and sputum from patients were regularly tested for SARS-CoV-2 virus detection by rRT-PCR during their ICU stay. The presence of SARS-CoV-2 in postmortem lung and kidney biopsies was also determined by rRT-PCR (Fig. 1). We did not find SARS-CoV-2 RNA in the kidneys of COVID19 patients in our cohort but did detect SARS-CoV-2 RNA in oro- and naso-pharyngeal swabs, sputum and in lung biopsies from the same patients (Fig. 1). The presence of bacterial co-infection was checked twice a week on a routine basis in all our patients. The patients routinely received a third-generation cephalosporin during the first 4 days of admission and continuous treatment of SDD paste (topical application of tobramycin, colistin, and amphotericin B in the oropharynx and stomach), 
as part of the selective decontamination of the digestive tract (SDD) treatment [17]. Three patients had a CVL or ECLS cannula-related infection with a coagulase-negative staphylococcus which were treated with vancomycin and line replacement.

\section{COVID-19-associated AKI is associated with severe and distinct histopathology}

We compared the renal histopathology from COVID-19 patients with bacterial sepsis-associated AKI patients (Fig. 2a). We found no evidence of glomerulopathy; tubulitis was observed in 1/6 COVID-19 patients and interstitial inflammation observed in $2 / 27$ patients with bacterial sepsis and 1/6 with COVID-19. Interstitial fibrosis and atrophy were observed in $7 / 27$ patients with bacterial sepsis and 1/6 with COVID-19. One of the most striking observations was the presence of thrombi in 5/6 COVID19 patients in the renal peritubular capillaries which was absent in biopsies from bacterial sepsis-AKI patients (Fig. 2a, c). Thrombi were additionally found in the glomeruli of 1 COVID-19 patient and 1 patient with sepsis. (Fig. 2a, c). An additional major finding was the extent of acute tubular necrosis (ATN). A degree of ATN was found in most, but not all, patients with bacterial sepsis, yet was present in all biopsies from COVID-19 patients. Morphology stage 2 ATN was the most common in both bacterial sepsis and COVID-19 patients and is associated with tubular vacuolization, tubular edema, epithelial cell flattening and some tubular cell apoptosis. ATN was found in small discontinuous groups of tubules throughout the renal tissue of $24 / 27$ bacterial sepsis patients. In contrast, all renal biopsies from COVID-19 patients had ATN which was also more extensively distributed throughout the total tissue area. Interestingly, we found extensive ATN in renal biopsies from 1 COVID-19 patient that did not have evidence of peritubular capillary thrombosis and was not clinically diagnosed with AKI implying that loss of renal tissue integrity precedes loss of renal function and besides ischemia, multiple other mechanisms might drive ATN (Fig. 2b). Importantly, we did not observe autolysis in our biopsies which allowed for an accurate quantification of ATN severity.

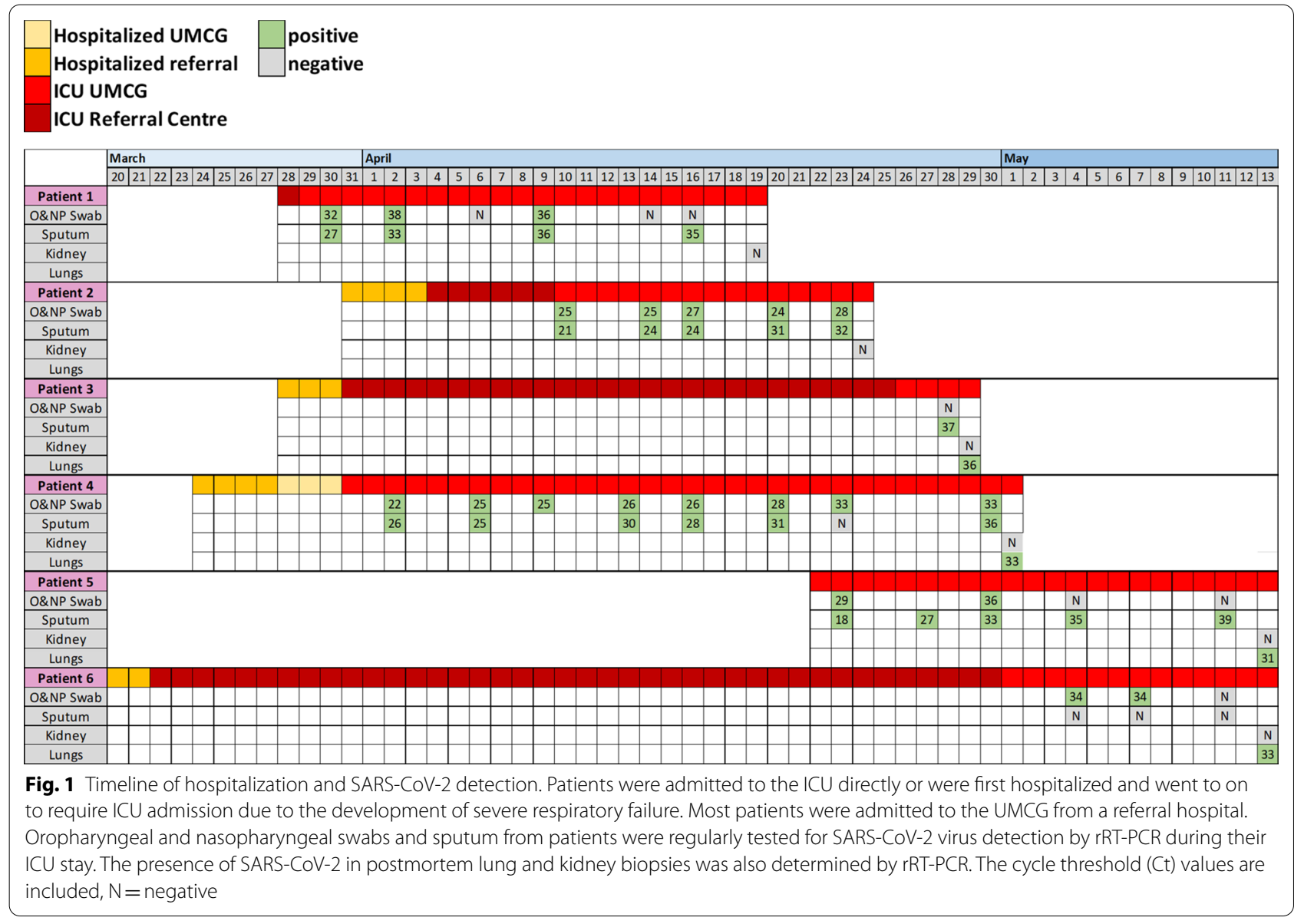




\begin{tabular}{|c|c|c|c|c|c|c|c|c|c|c|c|c|c|c|c|c|c|c|c|c|c|c|c|c|c|c|c|c|c|c|c|c|}
\hline \multirow[b]{2}{*}{ Patient ID } & \multicolumn{26}{|c|}{ SEPSIS } & & \multicolumn{5}{|c|}{ COVID-19 } \\
\hline & 1 & 2 & 3 & 4 & 5 & 6 & 7 & 8 & 9 & 10 & 11 & 12 & 13 & \begin{tabular}{|l|l|}
314 \\
\end{tabular} & 415 & 16 & 17 & 18 & 19 & 20 & 21 & 22 & 23 & 24 & \begin{tabular}{l|l}
25 & 2 \\
\end{tabular} & \begin{tabular}{l|l}
26 & 27 \\
\end{tabular} & & 1 & \begin{tabular}{l|l}
2 & 3 \\
\end{tabular} & \begin{tabular}{|l|l|}
3 & 4 \\
\end{tabular} & 5 & 6 \\
\hline ATN Morphology Stage & 2 & 2 & 2 & 2 & 3 & 0 & 2 & 2 & 2 & 2 & 2 & 1 & 2 & 0 & 2 & 2 & 2 & 3 & 2 & 2 & 2 & 2 & 0 & 1 & \begin{tabular}{|l|l}
1 & 1 \\
\end{tabular} & \begin{tabular}{l|l}
1 & 2 \\
\end{tabular} & & 2 & \begin{tabular}{l|l}
2 & 2 \\
\end{tabular} & \begin{tabular}{l|l|}
2 & 1 \\
\end{tabular} & 2 & \\
\hline \begin{tabular}{|l} 
ATN Extensiveness \\
\end{tabular} & 1 & 1 & 1 & 1 & 4 & 0 & 1 & 1 & 1 & 1 & 1 & 1 & 1 & 0 & 1 & 1 & 1 & 3 & 2 & 1 & 1 & 2 & 0 & 1 & \begin{tabular}{|l|l}
1 & 1 \\
\end{tabular} & \begin{tabular}{l|l}
1 & 3 \\
\end{tabular} & & 2 & \begin{tabular}{l|l}
3 & 3 \\
\end{tabular} & \begin{tabular}{l|l}
3 & 2 \\
\end{tabular} & 2 & 1 \\
\hline Tubulitis & 0 & 0 & 0 & 0 & 0 & 0 & 0 & 0 & 0 & 0 & 0 & 0 & 0 & 0 & 0 & 0 & 0 & 0 & 0 & 0 & 0 & 0 & 0 & 0 & \begin{tabular}{|l|c}
0 & 0 \\
\end{tabular} & \begin{tabular}{l|l}
0 & 0 \\
\end{tabular} & & 0 & \begin{tabular}{l|l}
0 & 0 \\
\end{tabular} & \begin{tabular}{l|l}
0 & 0 \\
\end{tabular} & 0 & 1 \\
\hline Interstitial inflammation (stage) & 0 & 0 & 0 & 0 & 0 & 0 & 0 & 0 & 1 & 0 & 0 & 0 & 0 & 1 & 0 & 0 & 0 & 0 & 0 & 0 & 0 & 0 & 0 & 0 & \begin{tabular}{|l|c|c|c|}
0 & 0 \\
\end{tabular} & \begin{tabular}{l|l}
0 & 0 \\
\end{tabular} & & 0 & \begin{tabular}{l|l}
0 & 0 \\
\end{tabular} & \begin{tabular}{l|l}
0 & 0 \\
\end{tabular} & 0 & 1 \\
\hline Interstitial fibrosis \& atrophy (IFTA-stage) & 1 & 0 & 1 & 0 & 0 & 0 & 0 & 1 & 0 & 1 & 0 & 0 & 0 & 1 & 0 & 0 & 0 & 1 & 0 & 0 & 0 & 0 & 0 & 0 & $\left.\begin{array}{|l|llll}1 & 0 & r\end{array}\right)$ & \begin{tabular}{l|l}
0 & 0 \\
\end{tabular} & & 0 & \begin{tabular}{l|l}
1 & 0 \\
\end{tabular} & \begin{tabular}{l|l}
0 & 0
\end{tabular} & 0 & 0 \\
\hline Glomerulitis & 0 & 0 & 0 & 0 & 0 & 0 & 0 & 0 & 0 & 0 & 0 & 0 & 0 & 0 & 0 & 0 & 0 & 0 & 0 & 0 & 0 & 0 & 0 & 0 & 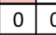 & \begin{tabular}{l|l}
0 & 0 \\
\end{tabular} & & 0 & \begin{tabular}{l|l}
0 & 0 \\
\end{tabular} & \begin{tabular}{l|l}
0 & 0
\end{tabular} & 0 & 0 \\
\hline Peritubular capillaritits & 0 & 0 & 0 & 0 & 0 & 0 & 0 & 0 & 0 & 0 & 0 & 0 & 0 & 0 & 0 & 0 & 0 & 0 & 0 & 0 & 0 & 0 & 0 & 0 & \begin{tabular}{|l|c|c|c|}
0 & 0 \\
\end{tabular} & \begin{tabular}{l|l}
0 & 0 \\
\end{tabular} & & 0 & \begin{tabular}{l|l}
0 & 1 \\
\end{tabular} & \begin{tabular}{l|l}
1 & 0 \\
\end{tabular} & 0 & 0 \\
\hline Increase of mesanglial matrix & 0 & 0 & 0 & 0 & 0 & 0 & 0 & 0 & 0 & 0 & 0 & 0 & 0 & 0 & 0 & 0 & 0 & 0 & 0 & 0 & 0 & 0 & 0 & 0 & \begin{tabular}{|l|c|c|c|}
0 & 0 \\
\end{tabular} & \begin{tabular}{l|l}
0 & 0 \\
\end{tabular} & & 0 & \begin{tabular}{l|l}
0 & 0 \\
\end{tabular} & \begin{tabular}{l|l}
0 & 0 \\
\end{tabular} & 0 & 0 \\
\hline Thrombi glomerular & 0 & 0 & 0 & 0 & 0 & 0 & 0 & 0 & 0 & 0 & 0 & 0 & 0 & 0 & 0 & 0 & 0 & 1 & 0 & 0 & 0 & 0 & 0 & 0 & \begin{tabular}{|l|c}
0 & $c$ \\
\end{tabular} & \begin{tabular}{l|l}
0 & 0 \\
\end{tabular} & & 0 & \begin{tabular}{l|l}
0 & 0 \\
\end{tabular} & \begin{tabular}{l|l}
0 & 1 \\
\end{tabular} & 0 & 0 \\
\hline Thrombi peritubular capillaries & 0 & 0 & 0 & 0 & 0 & 0 & 0 & 0 & 0 & 0 & 0 & 0 & 0 & 0 & 0 & 0 & 0 & 0 & 0 & 0 & 0 & 0 & 0 & 0 & \begin{tabular}{|l|l}
0 & 0 \\
\end{tabular} & \begin{tabular}{l|l}
0 & 0
\end{tabular} & & 0 & \begin{tabular}{l|l|l}
1 & 1 \\
\end{tabular} & \begin{tabular}{l|l}
1 & 1 \\
\end{tabular} & 1 & 1 \\
\hline
\end{tabular}

B

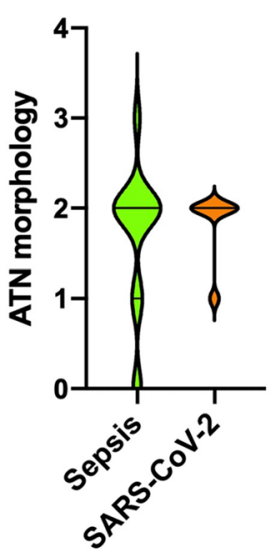



C

SEPSIS \#18
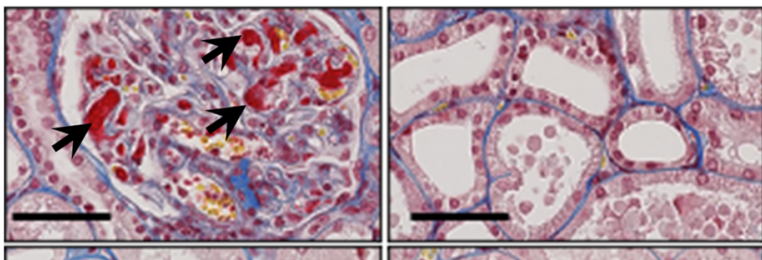

SEPSIS \#22

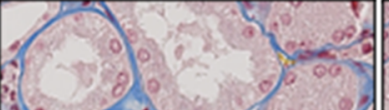

SEPSIS \#3
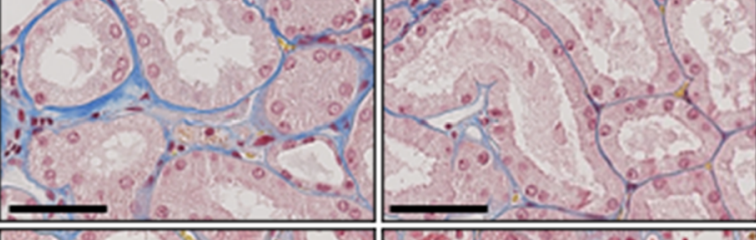

COVID \#5
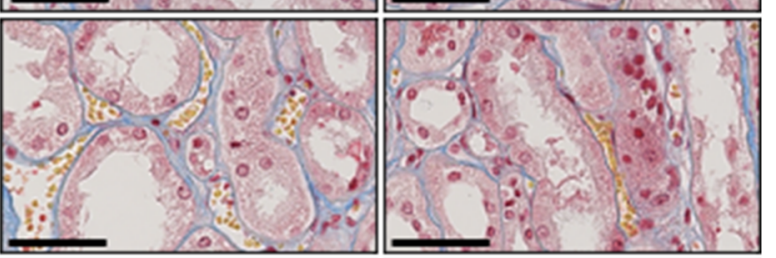

COVID \#6
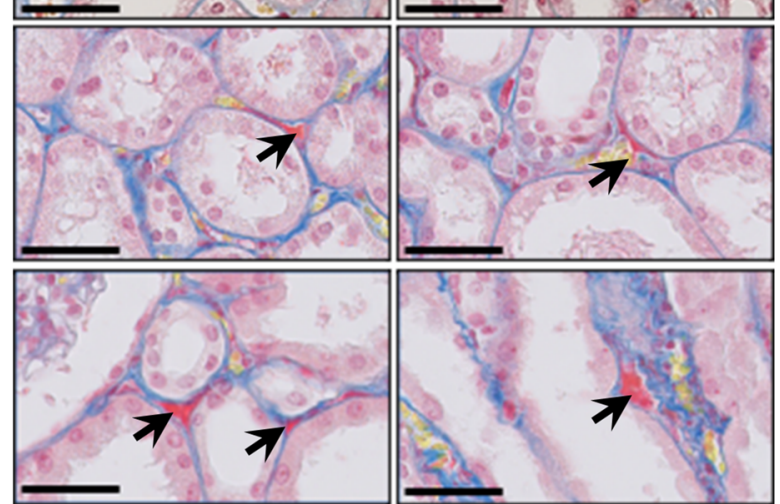

Fig. 2 a Renal histopathology findings in postmortem biopsies from bacterial sepsis and COVID-19 patients. Histopathology was scored using the scoring system described in Additional file 1: Table S1. b Quantification of acute tubular necrosis (ATN) morphology and ATN extensiveness in bacterial sepsis $(n=27)$ and COVID-19 patients $(n=6)$. c Representative Martius Scarlett Blue histochemical staining of kidney biopsies from bacterial sepsis and COVID-19 patients. Representative images were taken from randomly selected patients. Arrows indicate microthrombi. Original magnification $\times 400$

\section{Renal ACE2 mRNA downregulation is not specific to COVID-19}

ACE2 receptors are expressed in various cell types present in the kidney and are thought to be the main functional receptor for SARS-CoV-2 [18]. However, other receptors such as CD147 have also been implicated to play a role in some cell types [19]. We found low renal ACE2 mRNA levels in both COVID-19 (fold change $0.42, p=0.0002$ ) and bacterial sepsis patients (fold change $0.24, p<0.0001)$ compared to control, whereas 
the mRNA levels of CD147 remained unaltered in renal tissue from COVID-19 and bacterial sepsis patients compared to control (Fig. 3). These findings suggest that renal ACE2 mRNA downregulation is not specific to COVID19 and might be a common feature of AKI in critically ill patients.

\section{Renal injury and inflammatory biomarker mRNA levels differ in critically ill patients with COVID-AKI from those associated with bacterial Sepsis-AKI}

In order to gain more knowledge on the possible mechanisms of renal failure in patients with COVID-19 and how that might result in the observed histopathology, we investigated the renal mRNA levels of genes involved in various cellular processes associated with renal failure. Since the extent of tubular injury in COVID-19 is more severe compared to patients with bacterial sepsis, we assumed that the mRNA levels of renal injury markers would be altered. However, renal NGAL and KIM-1 mRNA levels in COVID-19 patients were comparable to normal renal tissue levels yet were increased in patients with bacterial sepsis (NGAL fold change 35, $p=0.046$, and KIM-1 fold change 24, $p=0.012$ ) (Fig. 4a). IGFBP7 mRNA levels were unaltered in patients with bacterial sepsis but were low in renal tissue from COVID-19 patients (fold change 0.46, $p=0.014$ ). In contrast, renal TIMP-2 mRNA levels were low in bacterial sepsis (fold change $0.4, p=0.017$ ) but not COVID-19 patients compared to normal controls (Fig. 4a). NGAL is known to be inflammation-driven, and the lack of NGAL upregulation might be attributed to a lack of renal inflammation since in COVID-19 patients the mRNA levels of renal IL-6, TNF $\alpha$ and MMP8 were similar to controls (Fig. 4b). Therefore, in COVID-19, the expression of renal injury and inflammatory markers suggests a different pattern of renal injury to that found in patients with bacterialsepsis. However, renal stress and injury responses are dynamic, and these findings could therefore be related to the timing of biopsy after disease onset.

\section{COVID-19-AKI is associated with distinct endothelial responses}

We proceeded to investigate genes regulating endothelial inflammatory activation and barrier integrity. Endothelial activation was absent in renal tissue from COVID-19 patients as indicated by the lack of E-selectin, VCAM-1 and ICAM-1 upregulation (Fig. 4c). Renal mRNA levels of CD31, PV-1 and VE-Cadherin did not differ from control individuals yet were increased in bacterial sepsis patients (CD31 fold change 2.3, $p=0.0006, \mathrm{PV}-1$ fold change 1.5, $p=0.008$ ) (Fig. $4 \mathrm{~d}$ ). In the kidney, Claudin-1, Claudin-5 and Occludin have a key role in mediating

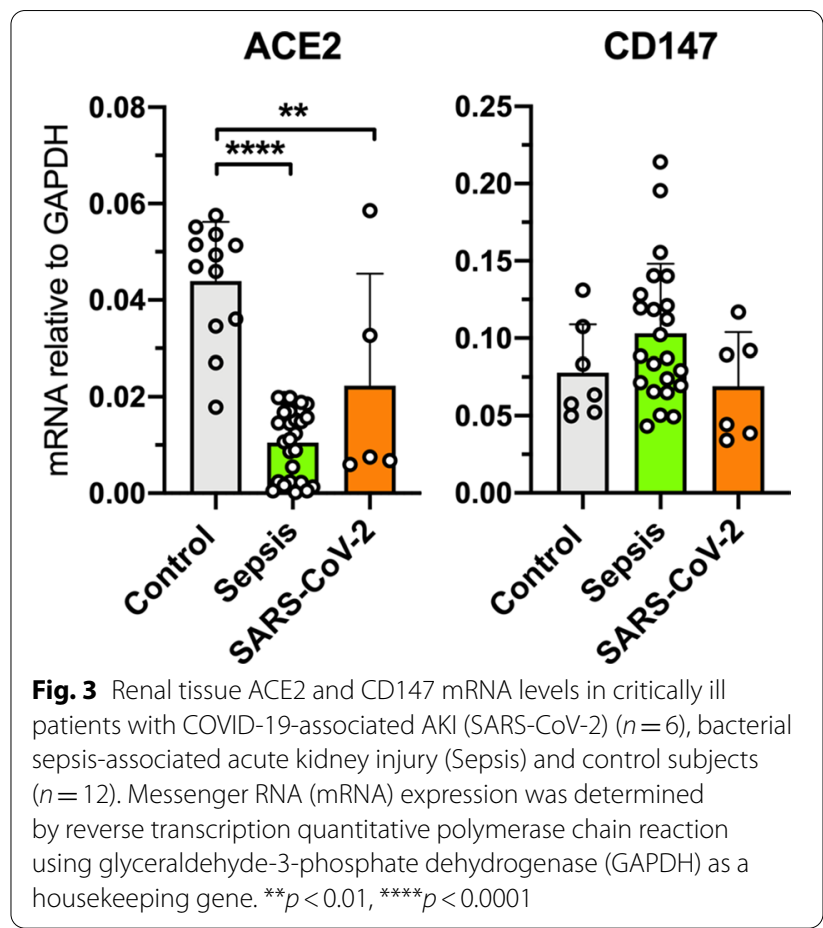

paracellular permeability to solutes [20, 21]. However, the mRNA levels of these molecules in COVID-19 and bacterial sepsis were comparable to control individuals (Fig. 4e). Ang1 mRNA levels were downregulated in renal tissue from both COVID-19 (fold change 0.27, $p<0.0001$ ) and bacterial sepsis patients (fold change 0.67 , $p<0.0001$ ) compared to controls (Fig. 4f). However, in contrast to patients with bacterial sepsis (fold change 3.1, $p=0.0215$ ), renal Ang2 mRNA levels in COVID-19 patients were comparable to controls. The Ang1/Ang2 ratio was therefore not disturbed in COVID-19 patients. Together these data suggest that at the time of death, distinct endothelial gene responses in COVID-19 compared to bacterial sepsis-AKI. However, we examined the final stage of disease and cannot exclude that endothelial responses at an earlier stage during the clinical course of COVID-19 were similar to those observed for bacterial sepsis.

Renal endothelial mRNA responses suggest impaired renal perfusion in COVID-19

Altered perfusion might be a crucial mechanism associated with AKI which could result in acute tubular necrosis. Tie 2 and KLF2 are genes shown to be responsive to altered blood flow [22]. Interestingly, we found Tie2 to be downregulated in renal tissue from COVID-19 patients compared to normal control (fold change 0.33, $p=0.037$ ) and bacterial sepsis patients suggesting aberrant renal perfusion in COVID-19-AKI patients (Fig. 4g). We also 
(See figure on next page.)

Fig. 4 a-h Renal mRNA levels of various genes in critically ill patients with COVID-19-associated AKI (SARS-CoV-2) $(n=6)$, bacterial sepsis-associated acute kidney injury (Sepsis) and control subjects $(n=12)$. Messenger RNA (mRNA) expression was determined by reverse transcription quantitative polymerase chain reaction using glyceraldehyde-3-phosphate dehydrogenase (GAPDH) as a housekeeping gene. ${ }^{*} p<0.05,{ }^{* *} p<0.01,{ }^{* * *} p<0.001$, **** $p<0.0001$

found a decreased VEGFR2/VEGFR3 ratio in bacterial sepsis (fold change $0.5, p<0.0001$ ) which was even more decreased in COVID-19-AKI (fold change 0.09, $p<0.0001$ ) (Fig. 4h). Combined with the decreased Tie2 levels this indeed suggests decreased renal blood flow.

\section{Discussion}

In order to develop better treatments for COVID-19 patients and especially with COVID-19-related AKI, we have to understand the mechanisms underlying these threatening sequelae better. In contrast to many recently published studies describing postmortem kidney pathology findings, we aimed to collect biopsies within $1 \mathrm{~h}$ after death since postmortem autodigestion of tissue can compromise histopathological findings and destruct RNA needed for molecular biology studies. Indeed, it was often not possible to accurately determine the degree of acute tubular injury due to severe autolysis in many tissue samples in various studies investigating postmortem kidney pathology [23, 24]. Therefore, we collected biopsies with a mean biopsy time of $21 \mathrm{~min}$ after death (range 6-40 min), thereby eliminating major autolytic changes in renal structure.

There is much debate as to whether SARS-CoV-2 can directly infect the kidney [25]. Recent reports in which SARS-CoV-2 RNA or protein was found located within the kidney, claim that direct infection of kidney epithelial cells can occur thereby inducing renal injury [26-31]. Similarly, other studies found SARS-CoV-2 RNA or nucleocapsid protein in the urine of COVID-19 patients which might also suggest direct viral infection of the kidney [32, 33]. However, not all studies examining renal pathology in COVID-19 corroborate these findings, and as an increasing number of studies with contradictory findings appear, it seems more plausible that there are subtypes of COVID-19-AKI: (1) direct viral infection, (2) renal failure as a result of secondary host response effects to SARS-CoV-2 infection, i.e., cytokine-mediated effects, damage-associated molecular pattern-mediated injury, complement-mediated damage [34], coagulation-mediated ischemia, or an as yet unrecognized mechanism leading to renal failure. We did not find SARS-CoV-2 RNA in the kidneys of COVID-19 patients in our cohort but did detect SARS-CoV-2 RNA in oral and nasopharyngeal swabs, as well as in lung biopsies from the same patients. We therefore assume that our patients do not have extra-respiratory viral tropism in the kidney and that we are investigating renal failure that resulted from secondary responses to SARS-CoV-2 infection. However, we examined the final stage of the disease and cannot exclude renal viral tropism at an earlier stage during the clinical course. The lack of renal TIMP-2, IGFBP7 and NGAL upregulation is not likely to be directly related to viral infection. It is known that NGAL is inflammatorydriven, and the lack of inflammation observed at the time of death corresponds with the lack of NGAL upregulation. However, we cannot exclude that renal NGAL or other renal injury and inflammatory markers were not altered at an earlier stage during the clinical course of the COVID-19.

ACE2 receptors are expressed in various cell types present in the kidney and are thought to be the main functional receptor for the SARS-CoV-2 virus [18]. However, other receptors such as CD147 have also been implicated to play a role in some cell types such as endothelial cells [19]. We found reduced renal ACE2 mRNA levels in both COVID-19 and bacterial sepsis patients compared to control, implying that reduced ACE2 mRNA expression is not specific to COVID-19, and that renal ACE2 mRNA downregulation might be a general feature of critically ill AKI patients.

The major histopathological findings in renal biopsies from COVID-19 patients in our cohort were ATN, which was present in all biopsies, and thrombi in the renal peritubular capillaries, which were found in biopsies in $5 / 6$ COVID-19 patients. In other postmortem COVID-19 biopsy studies, ATN is also reported although the extent varies [8, 23, 34-39]. Thrombi in peritubular capillaries were rarely observed in other studies. However, one study reported an incidence of fibrin thrombi of $75 \%$ [35]. Three other studies reported incidences of microthrombi varying from 4.5 to $14 \%$ [23, 28, 38]. Microthrombi in peritubular capillaries were reported without specification of the incidence in one study [39]. Renal inflammation and endothelial activation were absent in COVID-19 patients as indicated by the lack of inflammatory cytokine and endothelial adhesion molecule upregulation. This may also explain the lack of observed interstitial inflammation in the kidney. Although there were no signs of endothelial activation, impaired endothelial integrity was identified. Renal mRNA levels of CD31, PV-1 and VE-Cadherin were reduced in COVID-19 compared to bacterial sepsis 




\section{B Inflammation}

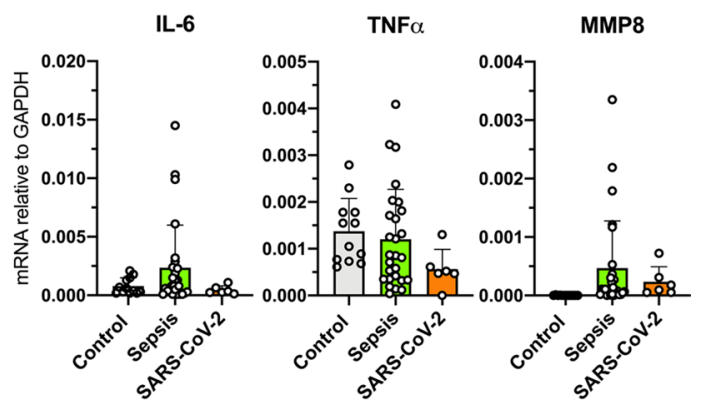

\section{Endothelial activation}

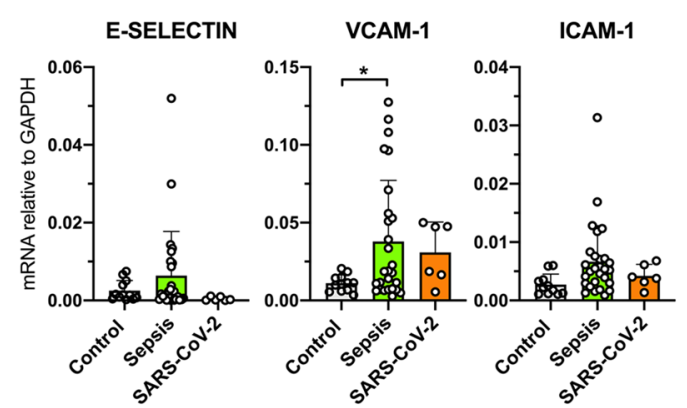

E Tight Junctions

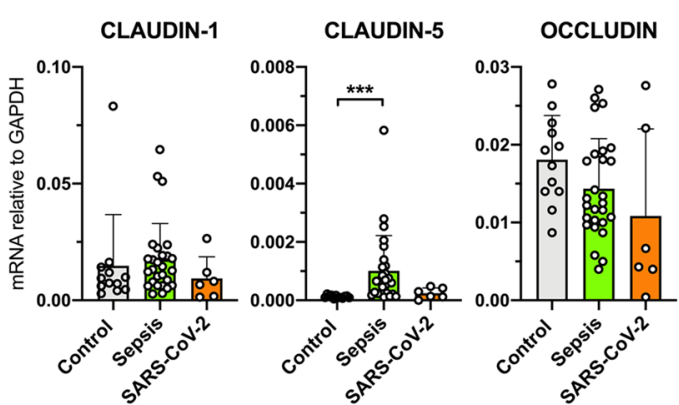

G Blood flow responsive genes

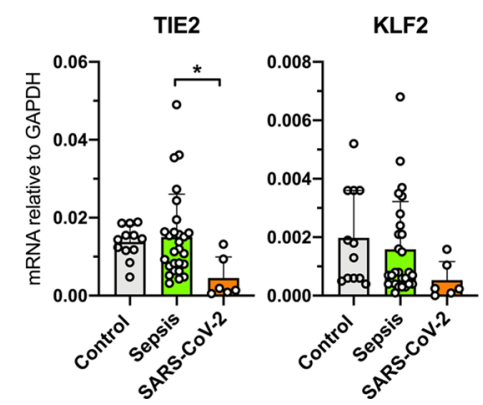

\section{Endothelial integrity}



F Angiopoietin signaling

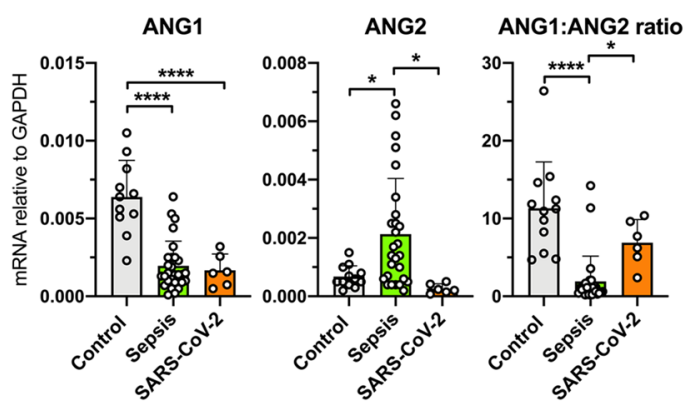

H VEGFR signaling

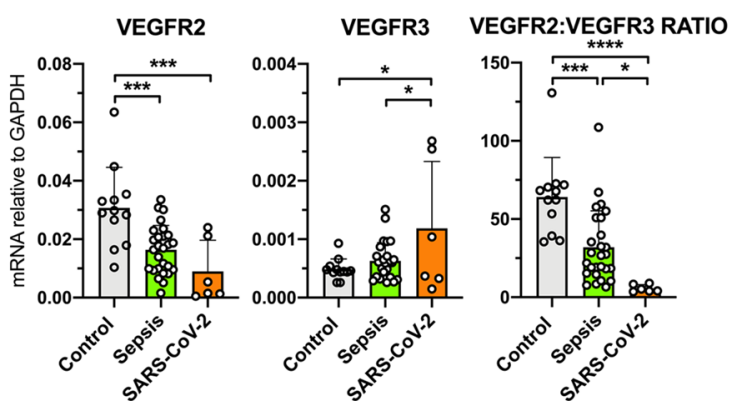


patients. Apart from maintaining endothelial integrity, PV-1 is involved in leukocyte transport and the repair of glomerular and peritubular capillary fenestration [40]. Loss of PV-1 mRNA may therefore mediate impaired endothelial barrier function. The angiopoietin signaling system is known to be important in regulating endothelial homeostasis [41]. When disturbed, inflammatory and hyperpermeability responses resulting in pulmonary and renal failure occur in critically ill patients [42]. Despite a reduction in Ang1 mRNA levels in renal tissue, Ang2 mRNA levels were unaltered and the Ang1/Ang2 ratio undisturbed in COVID-19-AKI patients. In patients with bacterial sepsis, the Ang1/Ang2 ratio is disturbed suggesting that the regulation of the angiopoietin system differs in late COVID-19 to bacterial sepsis. These results might even suggest that targeting this system therapeutically during the late stages of disease might have limited value in COVID-19-associated renal failure.

Microvascular endothelial flow responses are tightly controlled. We found Tie2 to be downregulated in renal tissue from COVID-19 patients compared to normal control and bacterial sepsis patients which was previously shown to be flow-dependent [22]. Apart from Tie2, the VEGF receptors VEGFR2 and VEGFR3 have also been shown to mediate flow responses. Therefore, when flow is disturbed, the VEGFR2/VEGFR3 ratio decreases [43]. We found a decreased VEGFR2/VEGFR3 ratio in bacterial sepsis which was even more decreased in COVID-19-AKI. Together, these results combined with the observed histopathology suggest that aberrant renal perfusion, perhaps as a result of the observed peritubular microthrombi, may contribute to the observed tubular injury and renal failure in COVID-19 patients. Supporting our findings, impaired renal blood flow was found in COVID-19 patients with AKI which was not attributed to changes in cardiac output or right ventricular function [44], implying indeed that renal microvascular dysfunction and microthrombi-based occlusion play a predominant role in COVID-19-AKI. In addition, albeit not in the kidney, decreased blood flow in sublingual capillaries in COVID-19 patients was recently described [45, 46]. Currently, no therapies are available for COVID-19-AKI. Our results and those of others suggest that normalizing and/or repairing the renal microvasculature might be a way to alleviate renal failure in critically ill patients with COVID-19.

Until now, the mRNA levels of genes involved in various cellular mechanisms driving AKI have not yet been investigated in COVID-19 patients. However, we acknowledge the following limitations of our study. First the number of COVID-19 patients in this study is 6 which is low. Additionally, patients with bacterial sepsis usually reside in the ICU for around 3-4 days, whereas
COVID-19 patients often remain ICU-bound for 2 or more weeks before recovery or death. At this late stage, inflammation and other pathophysiological mechanisms might have resolved which could have had an impact on the results of this study. However, death is a definitive endpoint with probably more similarity between bacterial sepsis and COVID-19 than any other time point during the clinical course of both diseases. Our findings have identified distinct histopathology and gene expression profiles between bacterial sepsis and late COVID-19 which might have important consequences for patient therapy before death. Due to the limited amount of renal tissue collected via percutaneous biopsies, we were limited in which analyses we could perform. Future studies need to be larger, focus on clinical heterogeneity and should investigate the correlation between mRNA and corresponding protein levels, as well as investigating soluble factors present in the plasma and how these factors relate to renal function.

\section{Conclusion}

COVID-19 was associated with severe ATN and microvascular thrombosis coupled with decreased microvascular flow, yet minimal inflammation. Further studies are required to determine whether these observations are a result of true pathophysiological differences or related to the timing of biopsy after disease onset.

\section{Abbreviations \\ AKI: acute kidney injury; ICU: intensive care unit; KDIGO: kidney disease improving global outcomes criteria; RIFLE: risk, injury, failure, loss of kidney function, and end-stage kidney disease; SARS-CoV-2: severe acute respiratory syndrome coronavirus 2.}

\section{Supplementary Information}

The online version contains supplementary material available at https://doi. org/10.1186/s13054-021-03631-4.

Additional file 1. Comparison of renal histopathology and gene expression profiles between severe COVID-19 and bacterial sepsis in critically ill patients.

\section{Acknowledgements}

The authors would like to thank Rianne Jongman and Marian Bulthuis for their excellent technical assistance.

\section{Authors' contributions}

MV performed kidney biopsies, provided the clinical data and was responsible for acquisition and interpretation of data as well as manuscript writing. DJV was responsible for acquisition, analysis and interpretation of data. MCvdH was responsible for acquisition, analysis and interpretation of data, including histopathological evaluation and scoring. MK provided SARS-CoV-2 PCR data and participated in the discussion. PJZ performed RT-qPCR experiments and provided data. JP performed the kidney biopsies and provided clinical data. SPB provided nephrological knowledge and participated in the discussion. PHJvdV obtained funding and participated in the discussion. JGZ was responsible for concept and design and manuscript writing. MvM performed the kidney biopsies and provided the clinical data, responsible for concept 
and design. JM was responsible for concept and design, manuscript writing, and took responsibility for the integrity of the data, the accuracy of the data analysis and statistical analysis. All authors read and approved the final version of the manuscript.

\section{Funding}

This work was supported by the ZonMw (Project Number: 10430012010006 ).

\section{Availability of data and materials}

The datasets used and/or analyzed during the present study are available from the corresponding author on reasonable request.

\section{Declarations}

\section{Ethics approval and consent to participate}

This study was approved by the UMCG Medical Ethical Committee (METC 2011/372)

\section{Consent for publication}

Not applicable.

\section{Competing interests}

The authors declare that they have no competing interests.

\section{Author details}

'Department of Critical Care, University of Groningen, University Medical Center Groningen, Hanzeplein 1, 9713 GZ Groningen, The Netherlands. ${ }^{2}$ Department of Pathology and Medical Biology, Pathology Section, University of Groningen, University Medical Center Groningen, Groningen, The Netherlands. ${ }^{3}$ Department of Clinical Microbiology and Infection Prevention, University of Groningen, University Medical Center Groningen, Groningen, the Netherlands. ${ }^{4}$ Department of Pathology and Medical Biology, Medical Biology Section, Laboratory for Endothelial Biomedicine and Vascular Drug Targeting Research, University of Groningen, University Medical Center Groningen, Groningen, The Netherlands. ${ }^{5}$ Department of Internal Medicine, University of Groningen, University Medical Center Groningen, Groningen, The Netherlands.

Received: 16 March 2021 Accepted: 6 June 2021

Published online: 10 June 2021

\section{References}

1. Yang X, Yu Y, Xu J, Shu H, Xia J, Liu H, et al. Clinical course and outcomes of critically ill patients with SARS-CoV-2 pneumonia in Wuhan, China: a single-centered, retrospective, observational study. Lancet Respir Med. 2020;8(5):475-81.

2. Zhou F, Yu T, Du R, Fan G, Liu Y, Liu Z, et al. Clinical course and risk factors for mortality of adult inpatients with COVID-19 in Wuhan, China: a retrospective cohort study. The Lancet. 2020;395:1054-62.

3. Guan W, Ni Z, Hu Y, Liang W, Ou C, He J, et al. Clinical characteristics of coronavirus disease 2019 in China. N Engl J Med. 2020;382:1708-20.

4. Chan L, Chaudhary K, Saha A, Chauhan K, Vaid A, Zhao S, et al. AKI in hospitalized patients with COVID-19. JASN. 2021;32(1):151-60.

5. Hamilton P, Hanumapura P, Castelino L, Henney R, Parker K, Kumar M, et al. Characteristics and outcomes of hospitalised patients with acute kidney injury and COVID-19. PLoS ONE. 2020;15:e0241544.

6. Hirsch JS, Ng JH, Ross DW, Sharma P, Shah HH, Barnett RL, et al. Acute kidney injury in patients hospitalized with COVID-19. Kidney Int. 2020;98:209-18

7. Mohamed MMB, Lukitsch I, Torres-Ortiz AE, Walker JB, Varghese V, Hernandez-Arroyo CF, et al. Acute kidney injury associated with coronavirus disease 2019 in urban New Orleans. Kidney360. 2020;1:614-22.

8. Golmai P, Larsen CP, DeVita MV, Wahl SJ, Weins A, Rennke HG, et al. Histopathologic and ultrastructural findings in postmortem kidney biopsy material in 12 patients with AKI and COVID-19. JASN. 2020;31:1944-7.

9. Nadim MK, Forni LG, Mehta RL, Connor MJ, Liu KD, Ostermann M, et al. COVID-19-associated acute kidney injury: consensus report of the 25th Acute Disease Quality Initiative (ADQI) Workgroup. Nat Rev Nephrol. 2020;16:747-64.
10. Aslan A, van den Heuvel MC, Stegeman CA, Popa ER, Leliveld AM, Molema G, et al. Kidney histopathology in lethal human sepsis. Crit Care. 2018:22:359.

11. Aslan A, van Meurs M, Moser J, Popa ER, Jongman RM, Zwiers PJ, et al. Organ-specific differences in endothelial permeability-regulating molecular responses in mouse and human sepsis. Shock. 2017;48:69-77.

12. Jou-Valencia D, Koeze J, Popa ER, Aslan A, Zwiers PJ, Molema G, et al. Heterogenous renal injury biomarker production reveals human sepsisassociated acute kidney injury subtypes. Crit Care Explor. 2019;1:e0047.

13. Singer M, Deutschman CS, Seymour CW, Shankar-Hari M, Annane D, Bauer $\mathrm{M}$, et al. The third international consensus definitions for sepsis and septic shock (sepsis-3). JAMA. 2016;315:801-10.

14. Bellomo R, Ronco C, Kellum JA, Mehta RL, Palevsky P. Acute renal failure: definition, outcome measures, animal models, fluid therapy and information technology needs: the Second International Consensus Conference of the Acute Dialysis Quality Initiative (ADQI) Group. Crit Care. 2004;8:R204-12.

15. Kellum JA, Lameire N. Diagnosis, evaluation, and management of acute kidney injury: a KDIGO summary (part 1). Crit Care. 2013;17:204.

16. Corman VM, Landt O, Kaiser M, Molenkamp R, Meijer A, Chu DK, et al. Detection of 2019 novel coronavirus (2019-nCoV) by real-time RT-PCR. Eurosurveillance. 2020;25:2000045.

17. de Smet AMGA, Kluytmans JAJW, Cooper BS, Mascini EM, Benus RFJ, van der Werf TS, et al. Decontamination of the digestive tract and oropharynx in ICU patients. N Engl J Med. 2009;360:20-31.

18. Hamming I, Timens W, Bulthuis MLC, Lely AT, Navis GJ, van Goor H. Tissue distribution of ACE2 protein, the functional receptor for SARS coronavirus. A first step in understanding SARS pathogenesis. J Pathol. 2004;203:631-7.

19. Ahmetaj-Shala B, Vaja R, Atanur SS, George PM, Kirkby NS, Mitchell JA. Cardiorenal tissues express SARS-CoV-2 entry genes and basigin (BSG/ CD147) increases with age in endothelial cells. J Am Coll Cardiol Basic Trans Sci. 2020;5(11):1111-23.

20. Prot-Bertoye C, Houillier P. Claudins in renal physiology and pathology. Genes. 2020;11(3):290.

21. Krug SM, Schulzke JD, Fromm M. Tight junction, selective permeability, and related diseases. Semin Cell Dev Biol. 2014;36:166-76.

22. Kurniati NF, Jongman RM, vom Hagen F, Spokes KC, Moser J, Regan ER, et al. The flow dependency of Tie2 expression in endotoxemia. Intensive Care Med. 2013;39:1262-71.

23. Santoriello D, Khairallah P, Bomback AS, Xu K, Kudose S, Batal I, et al. Postmortem kidney pathology findings in patients with COVID-19. JASN. 2020;31:2158-67.

24. Remmelink M, De Mendonça R, D'Haene N, De Clercq S, Veroca C, Lebrun $\mathrm{L}$, et al. Unspecific post-mortem findings despite multiorgan viral spread in COVID-19 patients. Crit Care. 2020;24:495.

25. Khan S, Chen L, Yang C-R, Raghuram V, Khundmiri SJ, Knepper MA. Does SARS-CoV-2 infect the kidney? JASN. 2020;31:2746-8.

26. Puelles VG, Lütgehetmann M, Lindenmeyer MT, Sperhake JP, Wong MN, Allweiss $L$, et al. Multiorgan and renal tropism of SARS-CoV-2. N Engl J Med. 2020;383:590-2.

27. Braun F, Lütgehetmann M, Pfefferle S, Wong MN, Carsten A, Lindenmeyer MT, et al. SARS-CoV-2 renal tropism associates with acute kidney injury. The Lancet. 2020;396:597-8.

28. Su H, Yang M, Wan C, Yi L-X, Tang F, Zhu H-Y, et al. Renal histopathological analysis of 26 postmortem findings of patients with COVID-19 in China. Kidney Int. 2020;98:219-27.

29. Kissling S, Rotman S, Gerber C, Halfon M, Lamoth F, Comte D, et al. Collapsing glomerulopathy in a COVID-19 patient. Kidney Int. 2020;98:228-31.

30. Farkash EA, Wilson AM, Jentzen JM. Ultrastructural evidence for direct renal infection with SARS-CoV-2. JASN. 2020;31(8):1683-7.

31. Hanley B, Naresh KN, Roufosse C, Nicholson AG, Weir J, Cooke GS, et al. Histopathological findings and viral tropism in UK patients with severe fatal COVID-19: a post-mortem study. Lancet Microbe. 2020;1:e245-53.

32. Sun J, Zhu A, Li H, Zheng K, Zhuang Z, Chen Z, et al. Isolation of infectious SARS-CoV-2 from urine of a COVID-19 patient. Emerg Microbes Infect. 2020;9:991-3.

33. Wang W, Xu Y, Gao R, Lu R, Han K, Wu G, et al. Detection of SARS-CoV-2 in different types of clinical specimens. JAMA. 2020;323(18):1843-4. 
34. Diao B, Wang C, Wang R, Feng Z, Tan Y, Wang H, et al. Human kidney is a target for novel severe acute respiratory syndrome Coronavirus 2 (SARSCoV-2) infection. medRxiv.2020;2020.03.04.20031120.

35. Duarte-Neto AN, Monteiro RAA, da Silva LFF, Malheiros DMAC, de Oliveira $E P$, Theodoro-Filho J, et al. Pulmonary and systemic involvement in COVID-19 patients assessed with ultrasound-guided minimally invasive autopsy. Histopathology. 2020;77:186-97.

36. Menter T, Haslbauer JD, Nienhold R, Savic S, Hopfer H, Deigendesch N, et al. Postmortem examination of COVID-19 patients reveals diffuse alveolar damage with severe capillary congestion and variegated findings in lungs and other organs suggesting vascular dysfunction. Histopathology. 2020;77:198-209.

37. Brook OR, Piper KG, Mercado NB, Gebre MS, Barouch DH, Busman-Sahay $K$, et al. Feasibility and safety of ultrasound-guided minimally invasive autopsy in COVID-19 patients. Abdom Radiol. 2021;46:1263-71.

38. Schurink B, Roos E, Radonic T, Barbe E, Bouman CSC, de Boer HH, et al. Viral presence and immunopathology in patients with lethal COVID-19: a prospective autopsy cohort study. Lancet Microbe. 2020;1:e290-9.

39. Rapkiewicz AV, Mai X, Carsons SE, Pittaluga S, Kleiner DE, Berger JS, et al. Megakaryocytes and platelet-fibrin thrombi characterize multi-organ thrombosis at autopsy in COVID-19: a case series. EClinicalMedicine. 2020;24:100434.

40. Stan RV, Tkachenko E, Niesman IR. PV1 is a key structural component for the formation of the stomatal and fenestral diaphragms. MBoC. 2004;15:3615-30.
41. van Meurs M, Kümpers P, Ligtenberg JJ, Meertens JH, Molema G, Zijlstra JG. Bench-to-bedside review: angiopoietin signalling in critical illness-a future target? Crit Care. 2009;13:207.

42. Parikh SM. The angiopoietin-Tie2 signaling axis in systemic inflammation. JASN. 2017;28(7):1973-82

43. Baeyens N, Nicoli S, Coon BG, Ross TD, Van den Dries K, Han J, et al. Vascular remodeling is governed by a VEGFR3-dependent fluid shear stress set point. eLife. 2015;4:e04645.

44. Watchorn J, Huang DY, Joslin J, Bramham K, Hutchings SD. Critically ILL COVID-19 patients with acute kidney injury have reduced renal blood flow and perfusion despite preserved cardiac function; a case-contro study using contrast enhanced ultrasound. Shock. 2021;55(4):479-87.

45. Rovas A, Osiaevi I, Buscher K, Sackarnd J, Tepasse P-R, Fobker M, et al. Microvascular dysfunction in COVID-19: the MYSTIC study. Angiogenesis. 2020;24:145-57.

46. Damiani E, Carsetti A, Casarotta E, Scorcella C, Domizi R, Adrario E, et al. Microvascular alterations in patients with SARS-COV-2 severe pneumonia. Ann Intensive Care. 2020;10:60.

\section{Publisher's Note}

Springer Nature remains neutral with regard to jurisdictional claims in published maps and institutional affiliations.
Ready to submit your research? Choose BMC and benefit from:

- fast, convenient online submission

- thorough peer review by experienced researchers in your field

- rapid publication on acceptance

- support for research data, including large and complex data types

- gold Open Access which fosters wider collaboration and increased citations

- maximum visibility for your research: over $100 \mathrm{M}$ website views per year

At BMC, research is always in progress.

Learn more biomedcentral.com/submissions 